\title{
Formulation and development of a savory granola bar with textured soya protein and dehydrated fish as a "source of protein"
}

\section{By}

\author{
H.M.D.B.Wijethunga
}

This Thesis submitted in partial fulfillment of the requirements for the Degree of Master of Food Science and Technology,

Department of Food Science and Technology, Faculty of Applied science, University of Sri Jayewardenepura, Sri Lanka M.Sc. 


\section{DECLARATION}

The work describe in this thesis was carried by me, under the supervision of Dr. (Mrs.) Indira Wickramasinghe and the report on this thesis has not been submitted in whole or in part of any other institution for another Degree/Diploma.

...... 09.1212015

Date

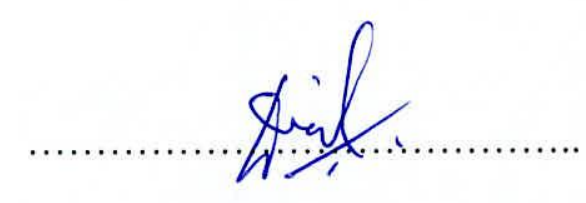

H.M.D.B. Wijethunga 


\section{DECLARATION OF THE SUPERVISOR}

I, Dr. (Mrs.) Indira Wickramasinghe certify that the above statement made by the candidate is true and this thesis is suitable for submission to the University for the purpose of evaluation.

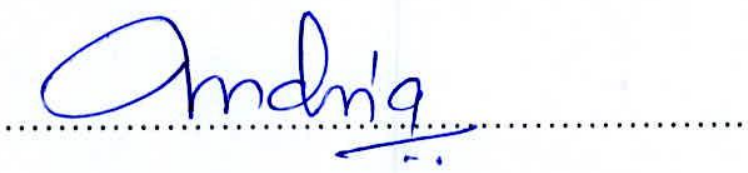

Dr. (Mrs.) Indira Wikramasinghe

Senior Lecturer,

Department of Food Science and Technology

Faculty of Applied Sciences,

University of Sri Jayewardenepura

Gangodawilla,

Nugegoda,

Sri Lanka. 


\section{TABLE OF CONTENTS}

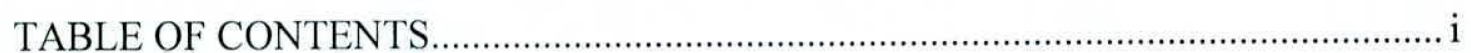

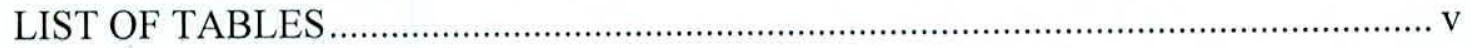

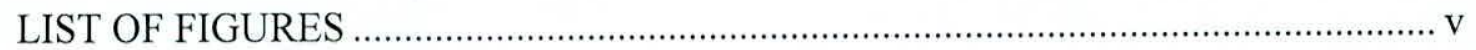

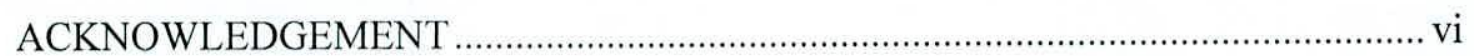

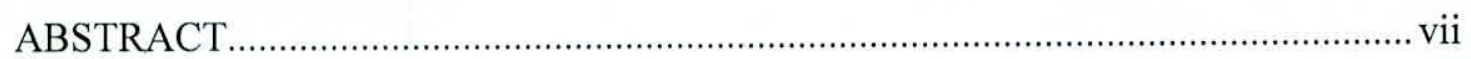

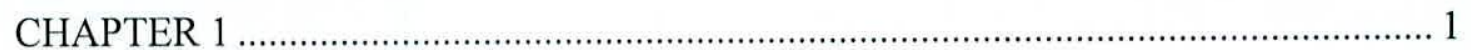

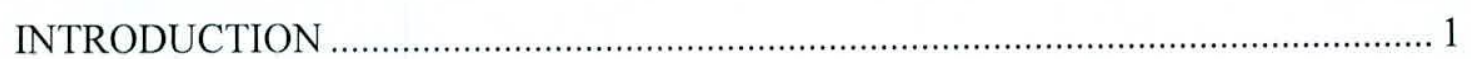

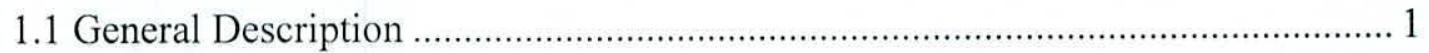

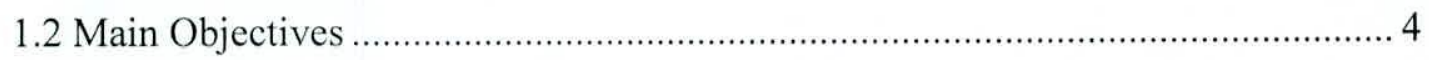

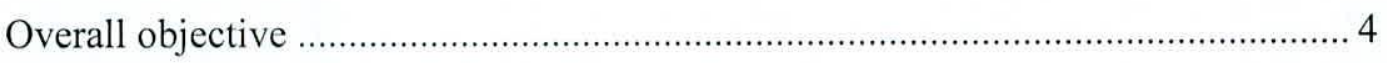

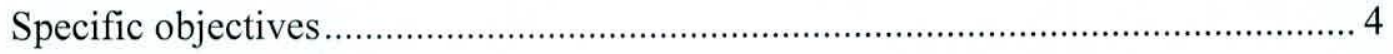

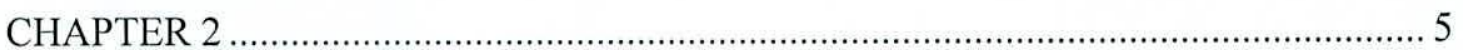

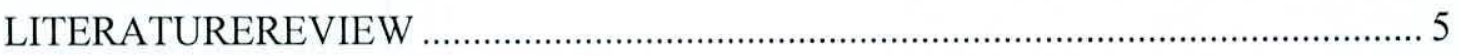

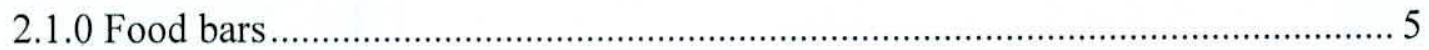

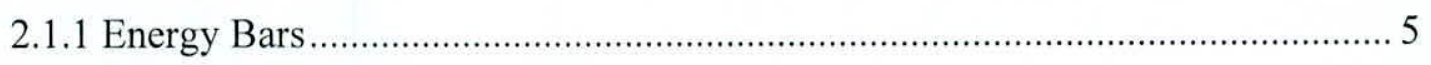

2.1.2Cereal \& Granola Bars ...................................................................................... 5

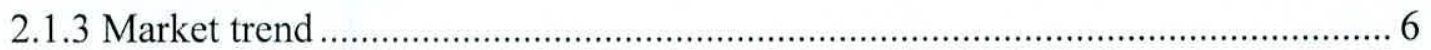

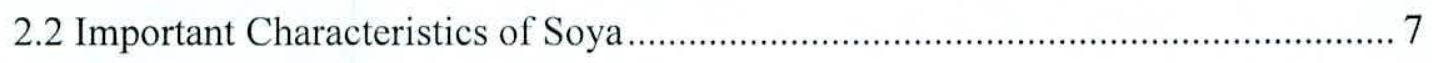

2.2.0 Scientific classification of soybean ....................................................................... 7

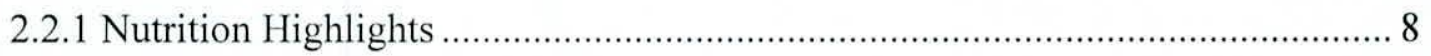

2.1.2 The making of textured soyaprotein …........................................................... 9

2.1.3 Health benefits of textured soya Protein .............................................................. 9

2.1.3.1 Hypolipidemic effects of soy protein and ISF ......................................... 10

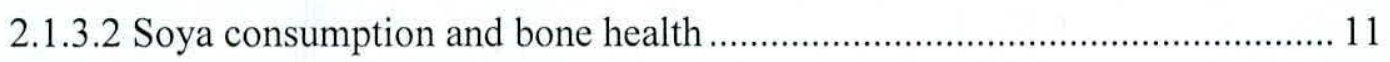

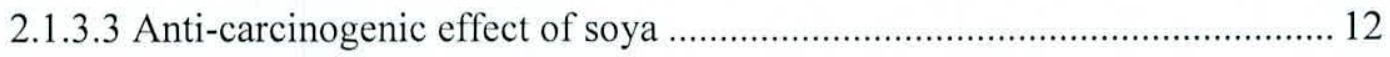

2.1.3.4 Effects of soya on the managing of diabetes mellitus ............................... 12

2.1.4 Nutritional facts of textured soya protein........................................................ 13

2.3 Important Characteristics of Maldive fish......................................................... 14

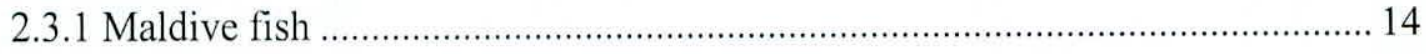




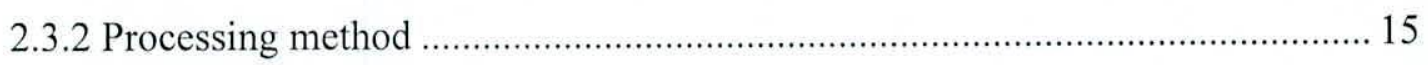

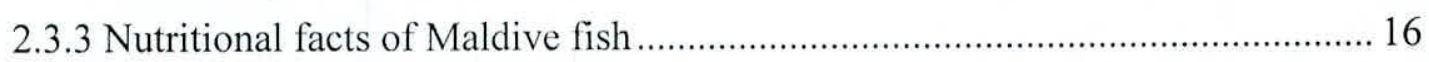

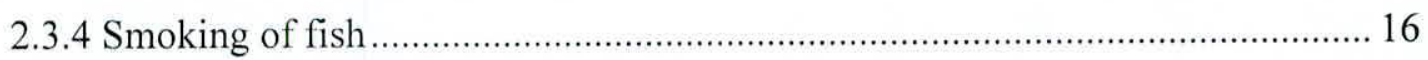

2.4Important Characteristics of Chili and Black pepper........................................... 18

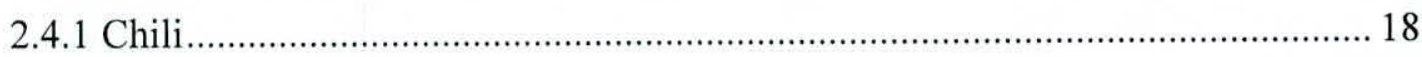

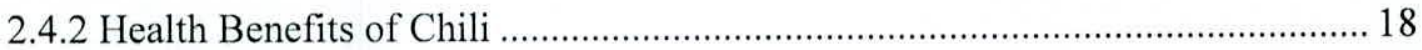

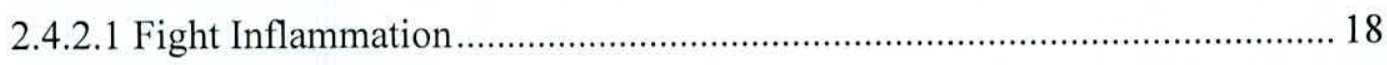

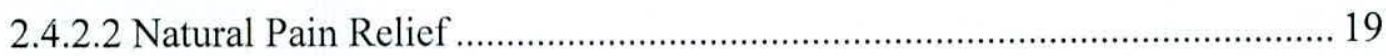

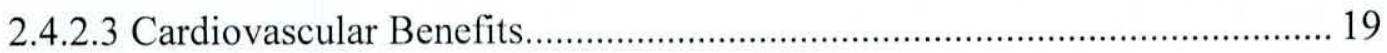

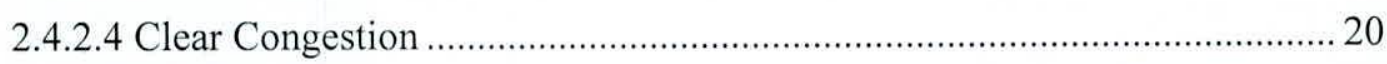

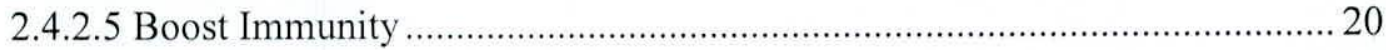

2.4.2.6 Help Stop the Spread of Prostate Cancer ................................................... 20

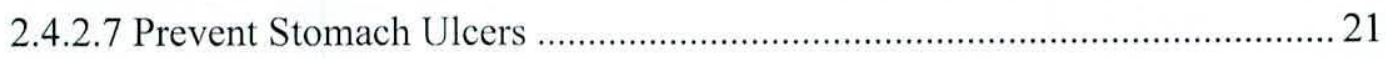

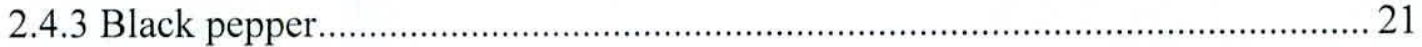

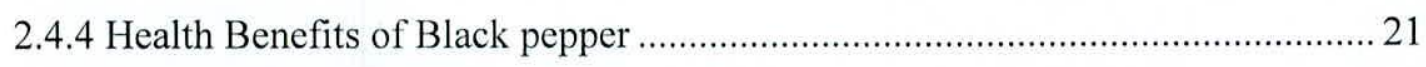

2.4.4.1 Improve Digestion and Promote Intestinal Health ................................... 21

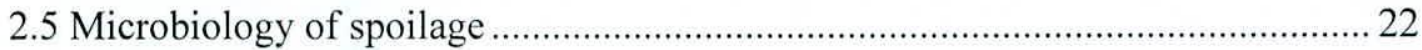

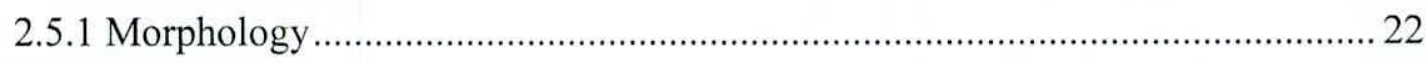

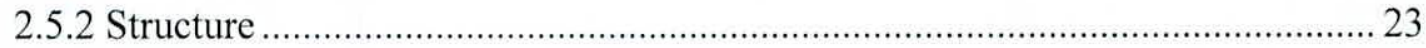

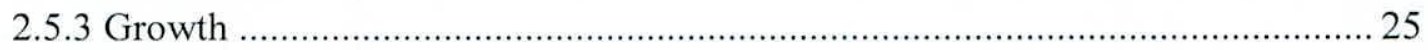

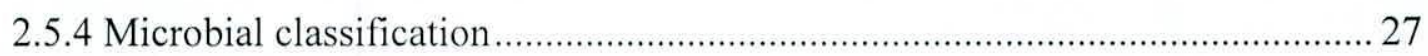

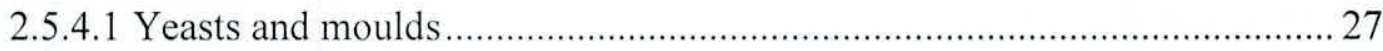

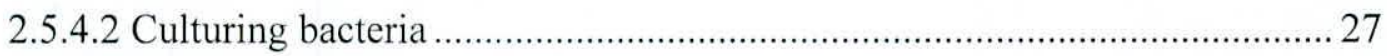

2.6 Important Characteristics of Granola bar binders ............................................... 29

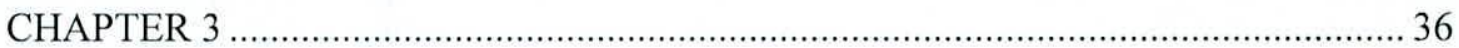

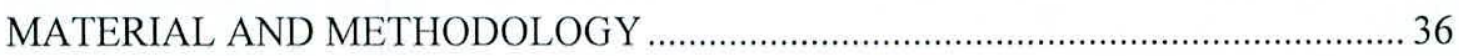

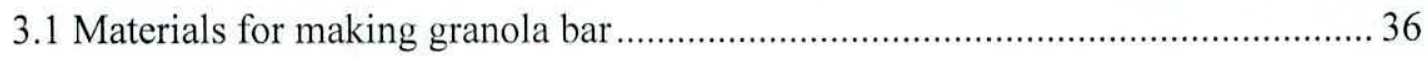

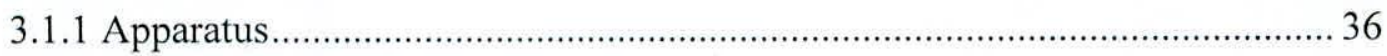

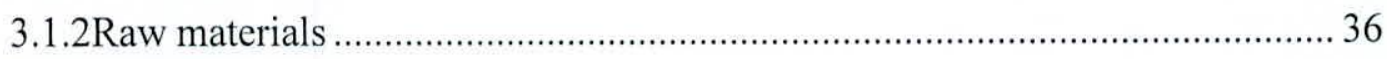

3.2 Preparing ingredients and making of granola bars.............................................. 37

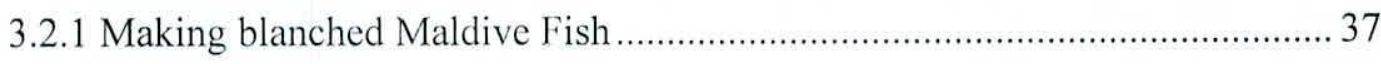




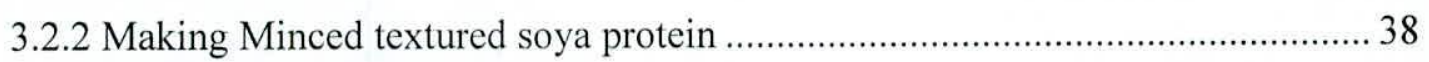

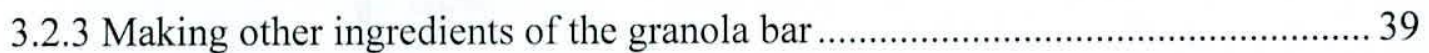

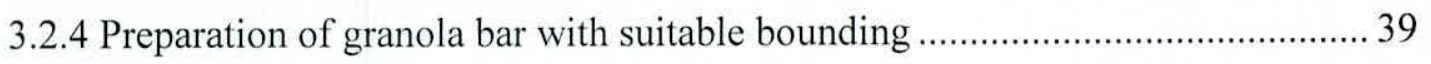

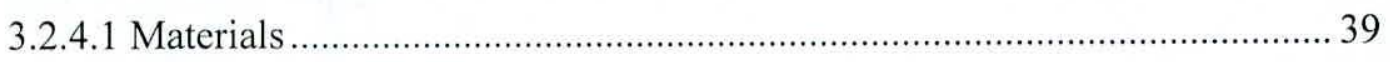

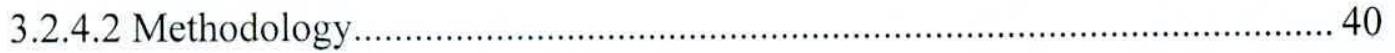

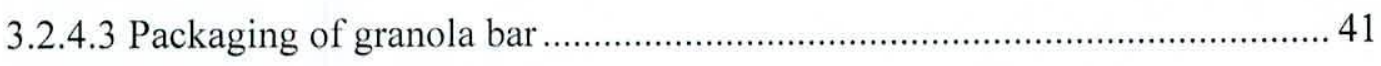

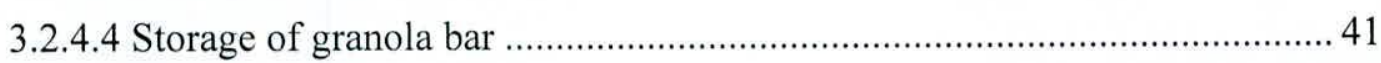

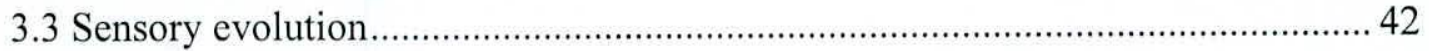

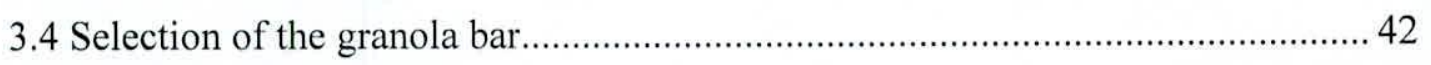

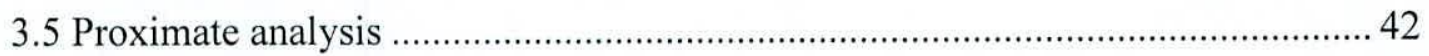

3.5.1 Determination of moisture content (Oven dry method) ................................... 42

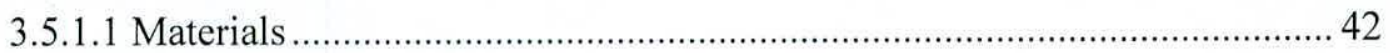

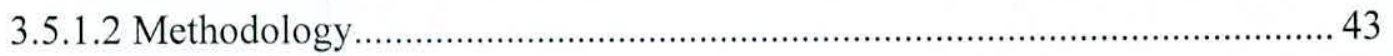

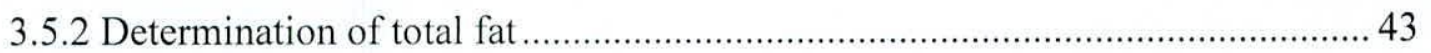

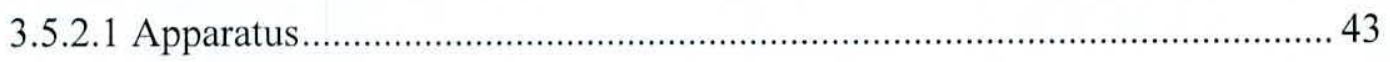

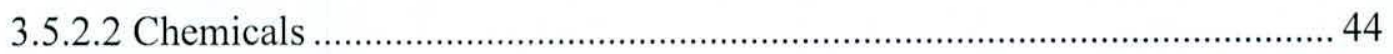

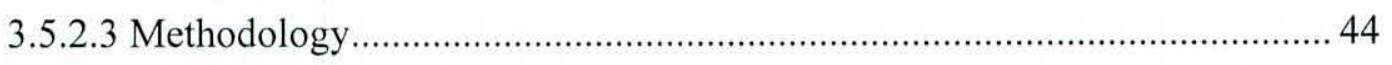

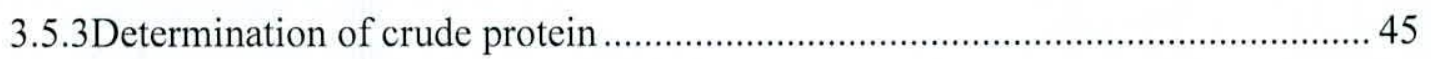

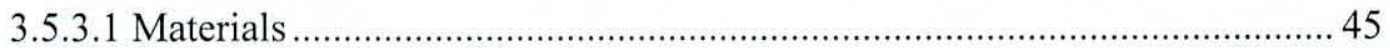

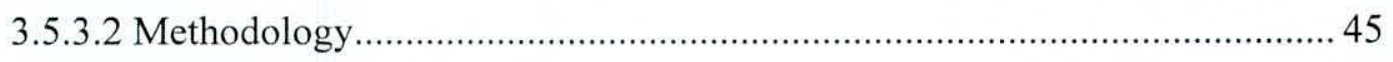

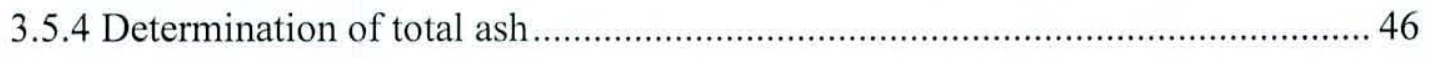

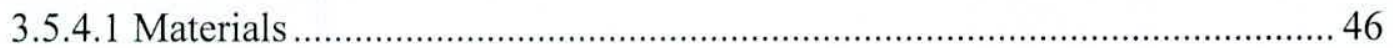

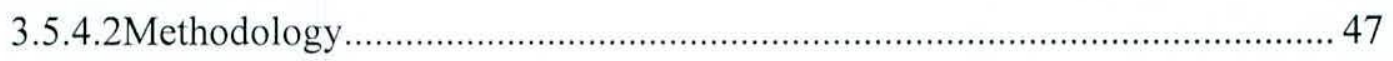

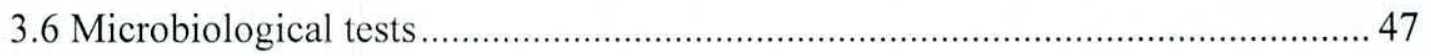

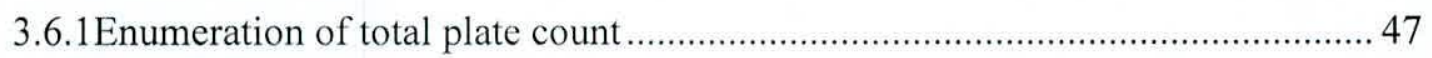

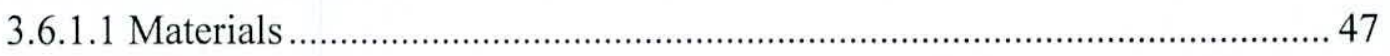

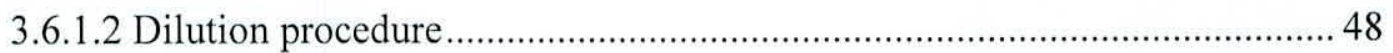

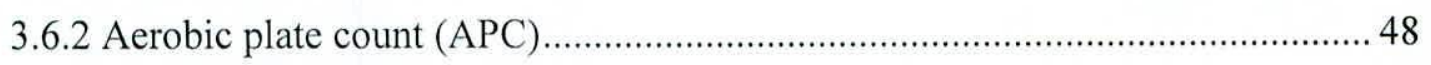

3.6.2.1 Medium: Standard Plate Count Agar (SPCA) ........................................... 48

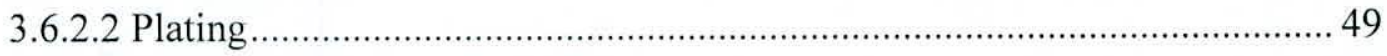

3.6.3 Most Probable number (MPN) method ........................................................ 49 
Coliforms test

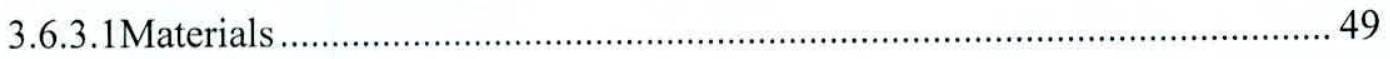

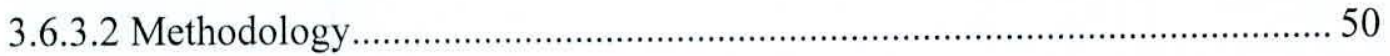

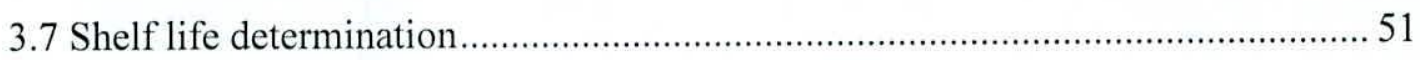

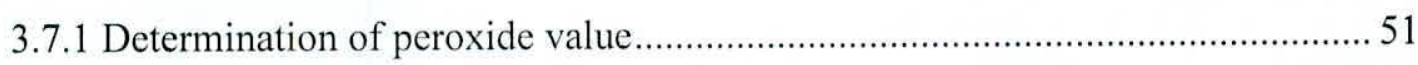

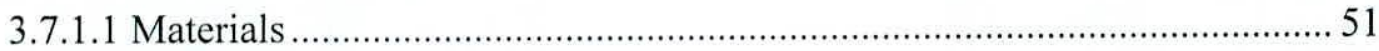

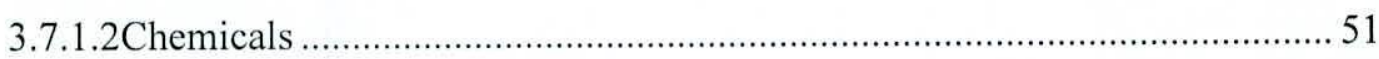

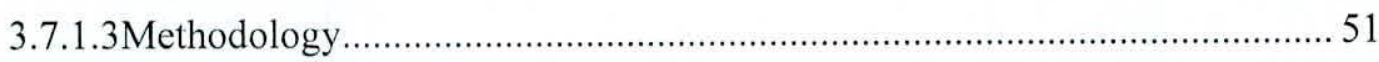

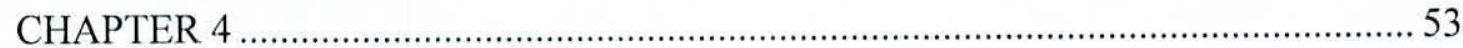

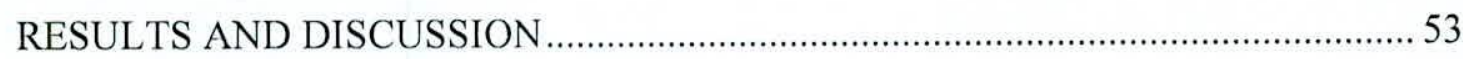

4.1 The preparation of the granola bar as "Source of Protein" .................................. 53

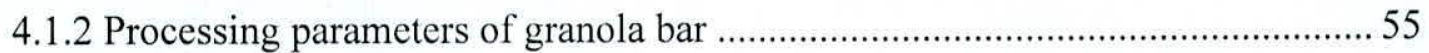

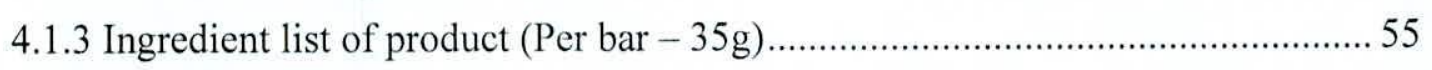

4.2 Sensory analysis for the selection of best granola bar formulation .......................56

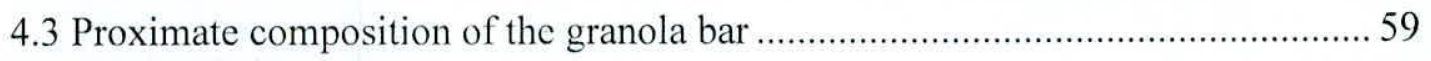

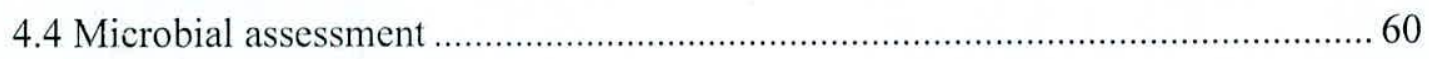

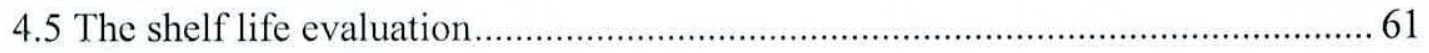

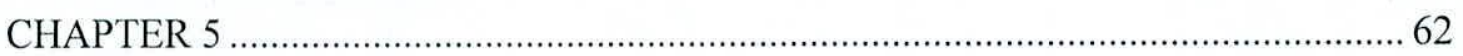

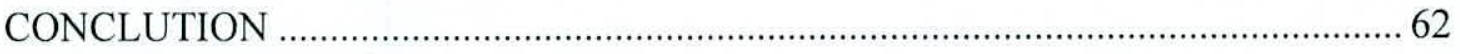

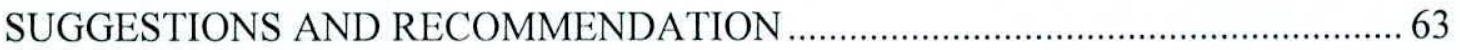

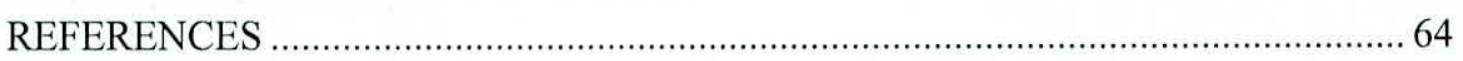

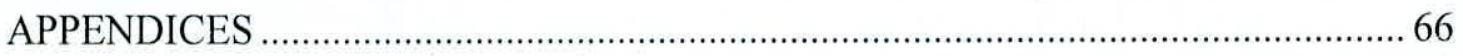

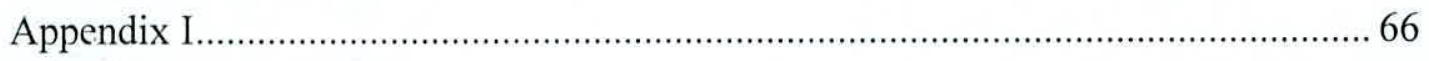

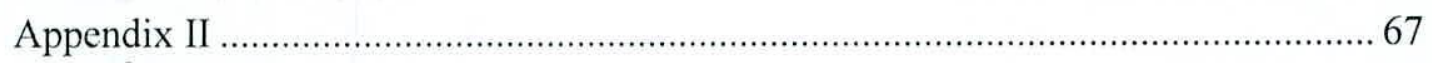

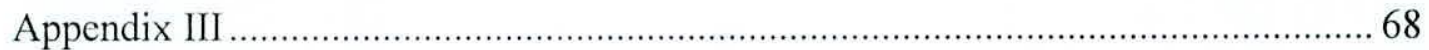

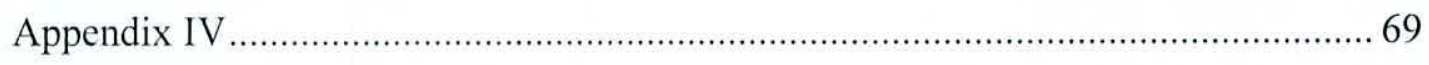

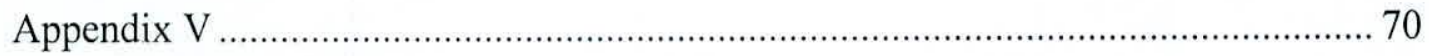

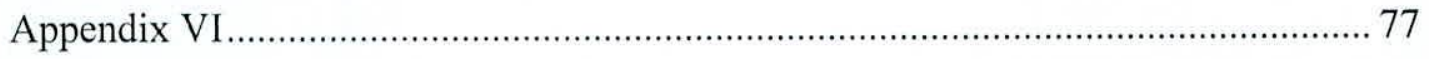

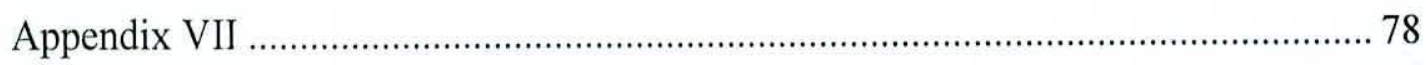

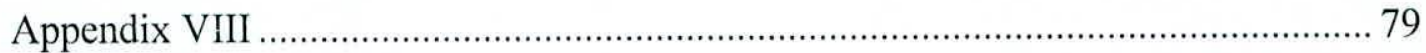




\section{LIST OF TABLES}

Table 2.1 - Nutritional information of Textured Soya Protein............................ 13

Table 2.2 - Nutritional information of Maldive fish .......................................... 16

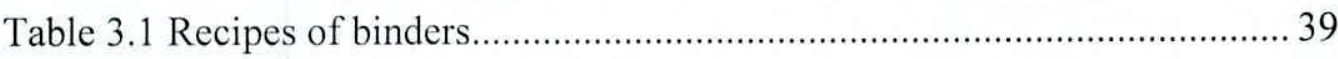

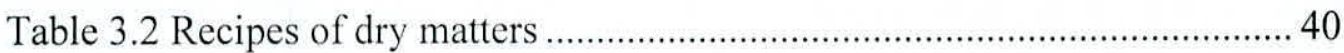

Table 4.1 - The estimated mean of the sensory values of the sample XY4, YZ5

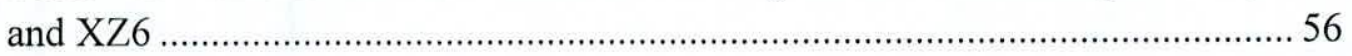

Table 4.2 -The estimated medians of the sensory values of sample XY4, YZ5

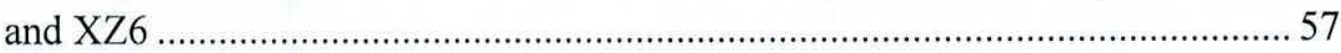

Table 4.3 - Nutritional Information of SAMPLE - XY4 ….................................. 59

Table 4.4 - Nutritional Information of SAMPLE - YZ5 …................................ 59

Table 4.5 - Nutritional Information of SAMPLE - XZ6 …................................... 60

\section{LIST OF FIGURES}

Figure 2.1 - Typical growth curve of bacteria/microbes .................................... 25

Figure 3.1 - Process of blanched Maldive Fish..................................................... 38

Figure 3.2 - Process of making Minced textured soya protein …....................... 38

Figure 4.1 -The estimated means of the sensory values of sample XY4, YZ5 and

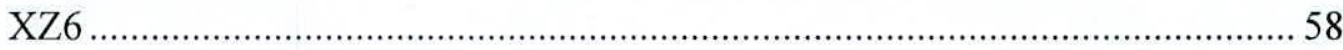

Figure 4.2 -The estimated medians of the sensory values of sample XY4, YZ5 and XZ6 


\section{ACKNOWLEDGEMENT}

First of all I would like to express my heartfelt gratitude to my project supervisor Dr. (Mrs.) Indira Wikramasinghe, for her valuable advises and guidance throughout the study.

I offer my sincere thanks to Mr.AnuraSenarathne - GM- QA and R\&D, Ceylon Biscuits Ltd, Dr. Jagath Wansapala, Prof. Arthur Bamunuaarachi, Dr. S.B. Nawarthne and Dr. (Mrs.)Rupika Perera, for giving me valuable assistance throughout the study.

I also like to thanks everyone in the Food Science laboratory at the University of Sri Jayewardenepura who helped me in various ways to conduct my research.

Finally I like to offer my thanks to my family members and friends for encouraging me to complete this project. 


\begin{abstract}
Protein rich composite Granola bar based on both plant and animal source ingredients were prepared manually and packed in flexible aluminum foil. Sensory evaluations, Proximate composition, as well as changes in peroxide value (PV) effect of water microbiological during storage under ambient $\left(15-34^{\circ} \mathrm{C}\right)$ temperature conditions were studied. Composite Granola bar remained its shelf stable for 3 months in ambient conditions.
\end{abstract}

The objective of the study was to formulate a notorious and economical savory granola bar using textured soya protein and maldive fish, as well as reduce the sugar amount and sweetness from the binder. Granola bar sample were evaluated organoleptically by a group of panelist using a statistically analyzing using one way ANOVA method to find the best formula.

Then proximate analysis was conducted to determine the nutrition composition of the granola bar. According to the food regulation of Sri Lanka granola bar weight and dimensions design for each serving size contain the above $12 \mathrm{~g}$ of protein. Bar serving size was $35 \mathrm{~g}$ and it should contain above $12 \mathrm{~g}$ of protein, and then it can be claimed as a "Source of protein".

Metalized flexible foil combination was design for keeping the product longer period and shelf life studies conducted for three months. The granola bar subjected to peroxide test and microbiological analysis at every two weeks.Further studies should be carried out for improving all the aspects of the finally developed granola bar.

Keywords: Source of Protein, Product acceptability, Packaging, Shelf stability 


\section{CHAPTER 1}

\section{INTRODUCTION}

\subsection{General Description}

The Granola bars are snacks of good sensory and nutritional characteristics due to their high proteins, carbohydrates, lipids, and mineral contents. Snack foods such as biscuits, fried chips, extruded products, chocolates available in market cannot meet the requirement of balanced diet. These are unhealthy offerings for the consumers especially protein required people. Increasing demand from consumers for protein, snacks has provoked the food manufacturers to develop protein contain granola bars that provide protein and other nutrition and convenience.

In Sri Lanka the consumption of fast food and snacks has been increased significantly in recent years, due to the trend of change in lifestyles. Many of modern-urban people don't have enough time to sit and take regular meals and so they simply move to the leisurely available snacks and fast foods. These reasons create the market for the preprepared and ready to eat snacks. But many varieties of those kinds of food items contain high amount of unsaturated lipids, cholesterol, sugars and salts which highly affect to human health and so those considered as unbalanced foods (junk foods). Also these foods contain artificial flavour, colours and MSG / I $+\mathrm{G}$ like unhealthy food additives. Today many of people are suffering diabetics and high serum Cholesterol level due to consume of unbalanced foods.

Food bars have better nutritional values than other fast foods and bakery products like buns, cakes, pastries, rolls, items which are considered as junk food. Further those are engaged in sports like body building, hiking mountains, as they are not too messy and 
occupy minimum space. Owing the growing consumer demand for healthy, natural and convenient food, attempts are being made to improve snack nutritional values via modifying their nutritive composition. Granola bars supply carbohydrates, protein, fat, vitamins, minerals, etc. It is considered as healthy food. Food bars advantages such as, being very convenient, fit into a briefcase, purse or pocket of working people, children or anyone and making them easily to take with individuals anywhere to eat anytime.

Having a product that keeps consumer satiated, consumers are able to decrease food intake without enduring high levels of hunger between meals by taking any junk food. In fact, granola bars do produce greater reduction in hunger and greater increases in fullness than conventional low-calorie food. The purpose of a protein granola bar is to reduce fatigue and improve concentration at vital time.

Granola bar is a cereal bar which contains cereal and multi grains. Energy bar does not belong to the confectionery segment but belongs to an emerging category called functional food, contains health promoting ingredients. These products are known as nutriceauticals. The commercially available snacks are generally highly unhealthy. They are energy dense but not provide nutrients vital to health.

These products are energy rich materials, fortified with a high fiber, complex carbohydrate, proteins, vitamins and minerals as well, making them healthier choice than a fast food option or a convenient store meal. When the fat content is considered, they have fat without high cholesterol level and saturated fat.

Truly effective food bars should provide fast-acting carbohydrate to facilitate ultraquick energy delivery. They also need a generous glucose content to help to ensure that a body is properly fuelled when it needs it most. 
Food bars are effective in weight loss, fat loss and overall body composition and dimension improvements, as well as satiety (feeling fullness) and taste acceptability. Food bars are a safe and effective method of weight loss because it keeps feeling satisfied, reducing unhealthy food intake between meals. Granola bar produce greater reduction in hunger and greater increases in fullness than conventional low-calorie food.

Food bars help consumer to eat right and to achieve and maintain a healthy body weight. By incorporating a sensible diet with moderate exercise, consumer too can achieve a healthier life style.

The greatest difficulty in obtaining a good cereal bar is the combination of several ingredients with specific functionality such as vitamins, minerals, proteins fibers, thickening agents, sweeteners and flavorings, and turns them into a product with flavor, texture ad decent appearance, while it tries to achieve specific nutrient goals.

In this research, the granola bar as formulated and developed using locally available raw materials and also with dehydrated fish with favorable consumer acceptance and also that research is carried out to make high protein granola bar. To select the best formulation of a product sensory analyzing process was used, which is based on fundamental psychological perception and physiological techniques. Hedonic scales are used by untrained consumers to select best formula of food bar. Proximate analysis was used to determine the protein, fat, fiber, ash contents and moisture percentage. Finally product shelf life was measured. The experimental works of the research were carried out at the laboratory of University of Sri Jayewardenepura. 


\subsection{Main Objectives}

\section{Overall objective}

To formulate a high amount of protein included and economical granola bar using minced soya meat (Textured soya protein), dehydrated fish and savory spices to legally claim as a "Source of Protein" according to Sri Lankan food regulation.

\section{Specific objectives}

$\checkmark$ To develop a savoury granola bar to can claim as a "Source of protein".

$\checkmark$ To include animal proteins include to granola bar.

$\checkmark$ To reduce the amount of sugar and sweet taste from binder.

$\checkmark$ To select the best formula by conducting sensory analysis.

$\checkmark$ To analyze the nutritional composition of the product.

$\checkmark$ To analyze the microbiological quality of the product.

$\checkmark$ To determine the Shelf life of the product. 


\section{CHAPTER 2}

\section{LITERATUREREVIEW}

\subsubsection{Food bars}

When people who are school students, office workers, when they are rush to their works, they don't have time for taking real time meal, they can take a granola bar instead of sitting meal. When they feel hungry in between breakfast and lunch and the afternoon they can take food bar instead of taking junk foods. There are many food bars are sophisticated for the meal eating occasions and age groups. There are two types of product categories such as breakfast/cereal/snack/granola and energy/nutrition bar format.

\subsubsection{Energy Bars}

Energy bars are supplemental bars containing cereals and other high energy foods targeted at people that require quick energy but do not have time for a meal. They are different from energy drinks, which contain caffeine, whereas bars provide food energy. Energy bars are being produced for giving more protein content than other food bars and making energy bar, giving protein by that is the main aim. When production energy bar, protein and fiber are added in to the food bars and add less sugar and use sweeteners instead of adding more sugar for make sweet taste.

\subsubsection{Cereal \& Granola Bars}

Granola has emerged as an important cereal mixture product. It is considered a ready-toeat (RTE) cereal, produced from the mixture of grain components with other ingredients such as chopped nuts and fruit pieces, through extensive processing, i.e. granulation. The principal grains used in the manufacture of granola include corn, rice, wheat, oats, barley and soya which are overall considered healthy ingredients (Pathare, 